\title{
Study of fatigue crack growth behavior of cold worked and aged TiNbSn alloys
}

\author{
Tiago Nunes Lima ${ }^{1}$ \\ Thiago Figueiredo Azevedo ${ }^{2 *}$ (1) \\ Luiz Carlos Pereira ${ }^{3}$ \\ Sandro Griza ${ }^{4}$
}

\begin{abstract}
Titanium alloys are used in several engineering fields. TiNbSn alloys have advantages with respect to mechanical properties, if compared to other titanium alloys. Cold worked TiNbSn alloys can undergoes elastic modulus less than half of the modulus of Ti6Al4V alloy, for example. The study aims to investigate the fatigue crack growth behavior (da/dN x $\Delta \mathrm{K})$ of cold worked and aged TiNbSn alloys according to the niobium $(\mathrm{Nb})$ and tin $(\mathrm{Sn})$ contents and heat treatment. Cold-rolled Ti35Nb2Sn, Ti42Nb2Sn and Ti42Nb alloys were manufactured with $55 \%$ engineering thickness reduction and aged at $400^{\circ} \mathrm{C}$ for 48 hours. The $42 \% \mathrm{Nb}$ content and aging heat treatment enhanced the crack growth behavior as in the Paris regime as in the crack growth threshold $\left(\mathrm{K}_{\text {th }}\right)$, which was attributed to the crack tortuosity exhibited by the alloys. The tortuosity leads to the roughness induced crack closure effect. The $\mathrm{K}_{\text {th }}$ increased with the aging due to the $\alpha$ precipitation in the $\beta$ grains.
\end{abstract}

Keywords: TiNbSn alloy; Cold working; Aging; Fatigue crack growth.

\section{Introduction}

Titanium alloys have a set of properties that make them very attractive for several engineering fields such as aeronautics, automotive, biomedical, defense and energy. Type $\beta$ titanium alloys have been evaluated due to their excellent combination of properties, which can be reached according to optimized alloy composition and manufacture processes.

Metastable $\beta$ titanium alloys can undergo a wide range of mechanical properties using the proper heat treatment such as aging. Furthermore, these ductile alloys can be easily cold worked. The literature denotes cold-worked $\beta$ titanium alloys as promising materials for both structural engineering - where high strength, good ductility and lightness are required, as well as for the biomedical field - where low elastic modulus and good corrosion resistance are also required in addition to the first mentioned mechanical properties [1]. Niobium and tin have been added to titanium due to their ability to stabilize $\beta$ phase at room temperature. These two alloy elements are biocompatible and act in some changes of properties of titanium alloys, such as the elastic modulus reduction [2]. Cold-worked and aged TiNbSn alloys hold potential of technological novelty, due to their set of attractive properties for use in high responsibility components [3-6].

Fracture mechanics approach is required in order to give the fracture toughness and fatigue crack growth rate behavior of the alloys. Several studies on $\mathrm{da} / \mathrm{dN} \mathrm{x} \Delta \mathrm{K}$ curves of titanium alloys were focused on Ti6Al4V alloy. Most of the crack growth rate data available concerning to titanium alloys is for tri-modal, Widmanstätten, or completely lamellar microstructures [7-10]. Moreover, limited data on crack growth rates of cold rolled $\beta$ titanium alloys are found in the literature $[5,11]$.

The crack growth test da/dN x $\Delta \mathrm{K}$ allows to know all the propagation stages of a given pre-existing crack. The linear behavior of the crack growth rate as a function of the increase in the stress intensity factor is expected for most metals within the Paris regime (region II of the da/ $\mathrm{dN}$ x $\Delta \mathrm{K}$ curve). However, crack growth rate data are not always linear in region II, but the crack growth curve can undergo changes in its slope, which can be attributed to microstructural transformations, depending on chemical content, thermomechanical processing and test environment [7,12-18]. Furthermore, crack closure effects can influence the crack growth rate behavior.

This study aimed to manufacture Ti35Nb2Sn, Ti42Nb2Sn and Ti42 $\mathrm{Nb}$ alloys in cold rolled condition with $55 \%$ engineering thickness reduction and aged at $400^{\circ} \mathrm{C}$ for 48 hours. These processing parameters were chosen due to the promising set of mechanical properties evidenced by previous

Senai Cimatec, Salvador, BA, Brasil

${ }^{2}$ Instituto Federal de Alagoas, Campus Coruripe, Coruripe, AL, Brasil

${ }^{3}$ Instituto Alberto Luiz Coimbra de Pós-graduação e Pesquisa de Engenharia - COPPE, Universidade Federal do Rio de Janeiro - UFRJ, Rio de Janeiro, RJ, Brasil

${ }^{4}$ Universidade Federal de Sergipe - UFS, São Cristóvão, SE, Brasil

*Corresponding author: thiago.azevedo@ifal.edu.br

2176-1523 (C) 2021. Lima et al. Published by ABM. This is an Open Access article distributed under the terms of the Creative Commons Attribution License, which permits unrestricted use, distribution, and reproduction in any medium, provided the original work is properly cited. 
studies $[2,6]$. The fatigue crack growth rate behavior of the alloys was discussed and complementary characterization methods allowed to explain the crack growth rate behavior differences between the alloys.

\section{Experimental procedures}

\subsection{Alloy's manufacturing}

The alloy's manufacturing were achieved as described in previous studies [6]. The procedure can be summarized as follows: alloys were obtained from commercial $\mathrm{Ti}, \mathrm{Nb}$ and $\mathrm{Sn}$ pure bars. The $280 \mathrm{~g}$ ingots were arc melted by means of a non-consumable tungsten electrode used under controlled argon atmosphere in a water-cooled copper crucible (Analog Instrumentation and Control, model AN9270). They were homogenized in argon atmosphere at $1000^{\circ} \mathrm{C}$ for 4 hours and left to cool inside the oven (model FL-1300 Maitec) after reaching the homogenization time. The ingots were then hot rolled at $850^{\circ} \mathrm{C}$, followed by water quenching, in order to obtain plates with $40 \%$ strain. Them, the cold rolling reduction of $55 \%$ were applied on the plates. Some plates were tested in the cold rolling condition, although others were in addition aged at $400^{\circ} \mathrm{C}$ for 48 hours. The tested alloys were named as follows:

- Ti35Nb2Sn Cold Rolled (Ti352CR);

- Ti52Nb2Sn Aged (Ti352A);

- Ti42Nb Cold Rolled (Ti420CR);

- Ti42Nb Aged (Ti420A);

- Ti42Nb2Sn Cold Rolled (Ti422CR);

- Ti42Nb2Sn Aged (Ti422A).

\subsection{Fatigue crack growth rate tests $(\mathrm{da} / \mathrm{dN} / \Delta \mathrm{K})$}

Specimens were machined for the fatigue crack growth rate tests (single notch 3-point bending type - SENB3).
The dimensions of the samples (Figure 1), as well as the other test procedures were defined according to the plate's thickness, following the appropriate standards (ASTM E399-19 [19], ASTM E1290-08 [20] and BS 7448-1 [21]). The dimensions of the specimens were as follows:

$$
\begin{aligned}
& \mathrm{W}=10 \mathrm{~mm} \text { (height); } \\
& \mathrm{B}=5 \mathrm{~mm} \text { (thickness); } \\
& \mathrm{L}=60 \mathrm{~mm} \text { (width, } \mathrm{L} \geq 4 \mathrm{~W}+10) ; \\
& \mathrm{S}=40 \mathrm{~mm} \text { (distance between supports); } \\
& \mathrm{a}_{\mathrm{n}}=3,2 \mathrm{~mm} \text { (notch); } \\
& \mathrm{a}_{0}=1 \mathrm{~mm} \text { (fatigue pre-crack); } \\
& \mathrm{h}=1 \mathrm{~mm} \text { (notch thickness). }
\end{aligned}
$$

The specimens were machined with the notch oriented in the direction perpendicular to the cold rolling direction (direction X-Y, Figure 2). The samples were tested by servohydraulic material test system (Landmark MTS 3010; $100 \mathrm{kN}$ ). According to BS ISO 12108 [22], Equation 1 gives the $\Delta \mathrm{K}$ to be applied in the cyclic loads.

$$
\Delta \mathrm{K}=\mathrm{K}_{\text {máx }}-\mathrm{K}_{\text {mín }}
$$

Equation 2 allows to give $\mathrm{K}_{\max }$ and $\mathrm{K}_{\min }$, from the loads $\mathrm{F}_{\text {max }}$ and $\mathrm{F}_{\text {min }}$, respectively.

$$
\mathrm{K}=\frac{\mathrm{F}}{\mathrm{BW}^{1 / 2}} \mathrm{~g}\left(\frac{\mathrm{a}}{\mathrm{W}}\right) 10^{1,5}
$$

The stress intensity factor function, $g(a / W)$, is given distinctively for each specimen configuration. For the SENB3 specimen, with support spacing of $4 \mathrm{~W}, \mathrm{~g}(\mathrm{a} / \mathrm{W})$ is given by Equation 3 .

$$
g\left(\frac{a}{W}\right)=\frac{6 \alpha^{1 / 2}}{\left[(1+2 \alpha)(1-\alpha)^{3 / 2}\right.}\left[1,99-\alpha(1-\alpha)\left(2,15-3,93 \alpha+2,7 \alpha^{2}\right)\right]
$$
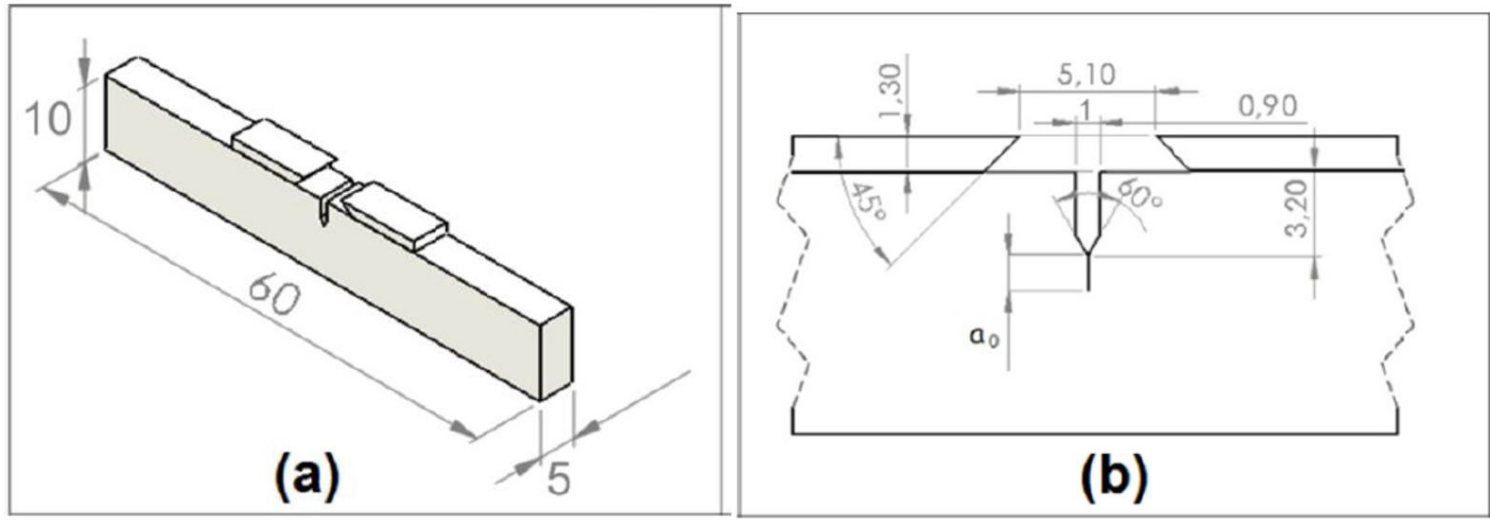

Figure 1. Representation of the specimen in millimeters. 
where:

$\alpha=\mathrm{a} / \mathrm{W}$, valid for $0 \leq \alpha \leq 1,0$;

$\mathrm{a}=$ crack size;

$\mathrm{F}_{\text {máx }}=$ Maximum load achieved in a given cycle;

$\mathrm{F}_{\min }=$ Minimum load achieved in a given cycle.

The tests were performed under the following conditions:

loading frequency of $10 \mathrm{~Hz}$; loading ratio $(\mathrm{R})$ of 0.1 ; sineshaped cyclic waves; room temperature; air environment and using the constant load test procedure. The latter was chosen to ensure $\Delta \mathrm{K}$ increases in order to give the crack growth rate in region II of the curve (linear region). MTS model $632.02 \mathrm{~F}-20$ clip gage was used to measure the crack size during the test. The crack growth rate measurements were started from the specimens containing the $\mathrm{a}_{0}$ fatigue pre-crack

Table 1. Result of the phase analysis found in the Azevedo et al. study [6]

\begin{tabular}{ccc}
\hline Material & Phases & Reference \\
\hline Ti352CR & $\mathrm{B}, \alpha$, and $\omega$ & {$[6]$} \\
Ti352A & $\mathrm{B}, \alpha ", \omega$ and $\alpha$ & {$[6]$} \\
Ti422CR & $\mathrm{B}, \alpha$, and $\omega$ & {$[6]$} \\
Ti422A & $\mathrm{B}, \alpha ", \omega$ and $\alpha$ & {$[6]$} \\
Ti420CR & $\mathrm{B}, \alpha$, and $\omega$ & {$[6]$} \\
Ti420A & $\mathrm{B}, \alpha ", \omega$ and $\alpha$ & {$[6]$} \\
\hline
\end{tabular}

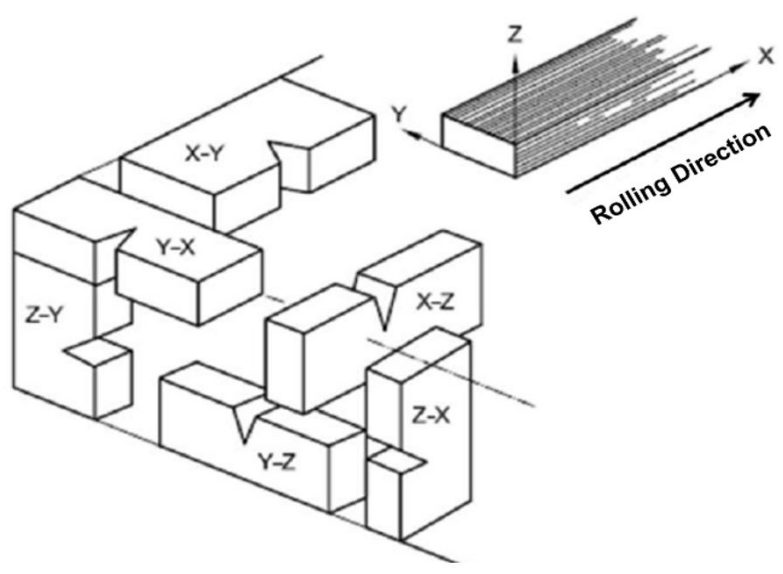

Figure 2. Different configurations for specimens' type SENB3.
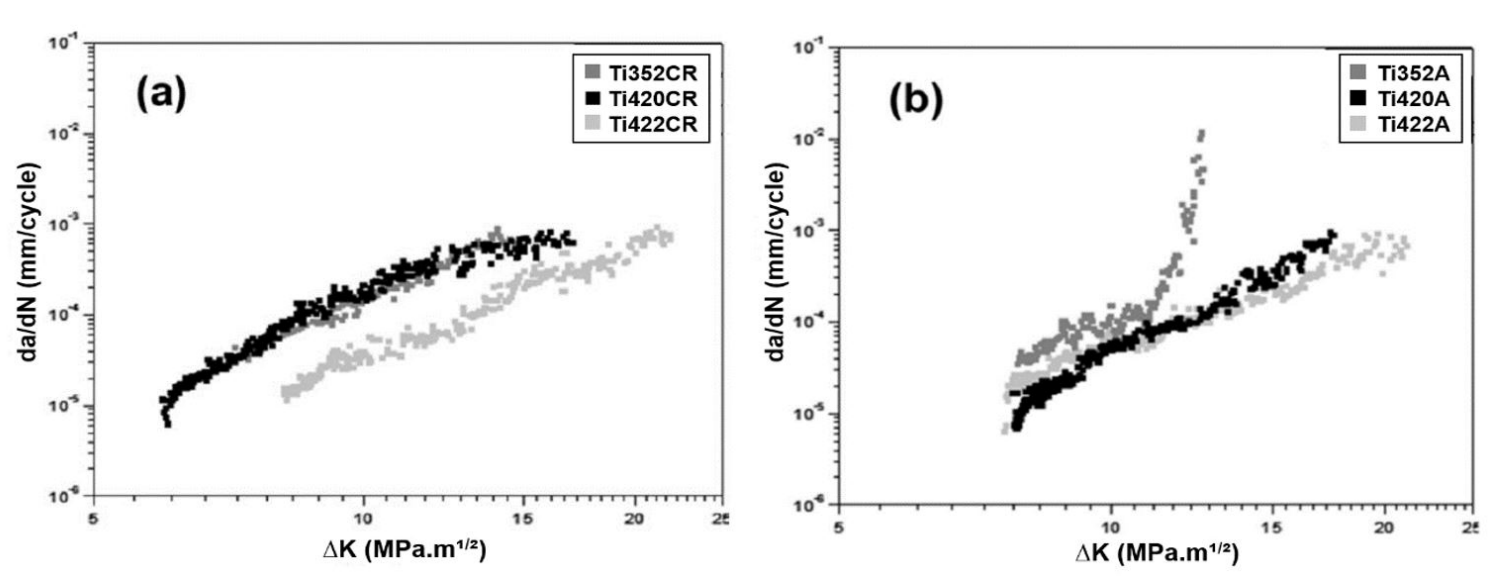

already produced. The crack opening displacement (COD) was constantly monitored during the fatigue cycles, which allows to give the correlation between instantaneous crack size and a given number of cycles. The stress intensity factor $\mathrm{dK}$ is given by Equations 1 and 2 for the same number of cycles. Then, the da/dN $x$ dK curve is easily given for a certain frequency of COD readings.

\subsection{Fracture analysis}

The cross section of the crack propagation direction was analyzed by metallography to evaluate the influence of the microstructure on the crack growth path. The metallographic samples were polished by alumina solution (particle size: $0.3 \mu \mathrm{m})$. The chemical etching was achieved through Kroll's solution ( $12 \mathrm{ml} \mathrm{HNO}_{3}, 6 \mathrm{ml} \mathrm{HF}$ and $82 \mathrm{ml} \mathrm{H}_{2} \mathrm{O}$ ). The microstructural features were analyzed by optical microscopy (Zeiss Axioscope A1).

The fracture analysis was performed by scanning electron microscopy (SEM - JEOL Carry Scope JCM-5700).

\section{Results and discussion}

\subsection{Fatigue crack growth rates}

In a previous study, the microstructure and phases of the same alloys studied in this paper were analyzed by microscopy and XRD analysis (Table 1). The cold rolled alloys hold the $\beta$ matrix, strain induced martensite $\alpha$ " and $\omega$ phase [6]. However, aging also encourages the $\alpha$ precipitation. Aging does not produce noticed microstructural changes in the alloys, if compared to the as worked condition [6]. However, the change in chemical content leads to noticeable microstructural changes. The Ti422 and Ti420 alloys with increased $\beta$ stabilizing elements ( $\mathrm{Nb}$ and $\mathrm{Sn})$, undergo microstructures of lower amount of $\alpha$ " needles [6].

Ti422CR and Ti422A alloys undergo better fatigue crack growth behavior (Figure 3), whereas Ti352CR and Ti420CR alloys presented results of crack growth rate higher than those of the Ti422CR alloy.

Figure 3. da/dN x $\Delta \mathrm{K}$ curves for (a) cold-worked and (b) aged alloys. 
The slope of the Ti420A alloy curve is greater than that of the Ti422A alloy. This means that the Ti420A alloy undergoes poor fatigue cracks growth performance at higher $\Delta \mathrm{K}$ values. Therefore, tin increased the fatigue crack growth performance at higher $\Delta \mathrm{K}$. The $\Delta \mathrm{K}$ thresholds were not possible to be obtained for the Ti352CR and Ti422CR alloys, as the $\Delta \mathrm{K}$ thresholds for these alloys are very low, which could only be given with the use of lower maximum loads during crack growth procedure. However, the tests showed that aging tends to increase the $\Delta \mathrm{K}$ threshold, which can be related to the precipitation of fine $\alpha$ precipitates [4,23-25]. Fine precipitates stress the $\beta$ matrix network and cause delay of the crack growth. Therefore, the increase in stress intensity is necessary in order to overcome the network stress and promote the crack progress. Furthermore, the dispersion of precipitates also arrests the crack growth, which leads to the need for more energy to circumvent or break the precipitates.

The Ti352A alloy performs better in respect to $\Delta \mathrm{K}$ threshold and crack growth rate in region II, although Ti352A alloy has lower $\Delta \mathrm{K}$ limit of unstable fracture (closer to $13 \mathrm{MPa} \sqrt{\mathrm{m}}$ ), if compared to the Ti352CR alloy (Figure 3). The aging of the Ti422 alloy did not cause significant change in region II. However, the aging of the Ti420 alloy caused significant change, increasing the limit (from $\sim 6$ to $\sim$ $8 \mathrm{MPa} \sqrt{\mathrm{m}}$ ) and decreasing the crack growth rate in region II. Table 2 compares the $\Delta \mathrm{K}$ threshold obtained in the present study with the values obtained in the literature for several different classes of materials. However, the $\Delta \mathrm{K}$ threshold

Table 2. $\Delta \mathrm{K}$ threshold for various classes of materials tested at a loading rate of 0.1

\begin{tabular}{ccc}
\hline Material & $\Delta \mathbf{K}_{\text {th }}(\mathbf{M P a} \sqrt{\mathbf{m}})$ & Reference \\
\hline Ti6A14V & $\sim 4,00$ & {$[26]$} \\
Ti62222S lamellar & $\sim 6,90$ & {$[27]$} \\
Ti62222S bimodal & $\sim 4,50$ & {$[27]$} \\
A1 7150 W51 underaged & $\sim 3,15$ & {$[28]$} \\
A1 7150 W51 peak aged (T6) & $\sim 2,65$ & {$[28]$} \\
A1 7150 W51 overaged (T7) & $\sim 2,30$ & {$[28]$} \\
Ti352A & $\sim 7,90$ & Present study \\
Ti422A & $\sim 7,67$ & Present study \\
Ti420CR & $\sim 6,00$ & Present study \\
Ti420A & $\sim 7,90$ & Present study \\
\hline
\end{tabular}

found in the present study were useful for the qualitative comparison among the tested materials, but cannot be viewed as quantitative results, since they were obtained by constant load method instead of the decreasing $\mathrm{dK}$ method.

Table 3 gives the constants "C" and " $\mathrm{m}$ " obtained from the Paris law for each material analyzed, as well as some titanium alloys found in literature. The Ti62222S alloys presented higher constant " $\mathrm{C}$ ", similar to the Ti420A alloy of our study. However, the constant " $m$ " was lower for the Ti62222S alloys, which denotes higher fatigue crack behavior. The lowest slope " $m$ " was founded in the Ti6Al4V alloy, which presented the highest constant " $C$ ".

The Ti422CR and Ti422A alloys have the highest "C" and lowest " $\mathrm{m}$ " of our study. Therefore, they perform better in relation to the crack growth if compared to the other TiNb alloys. The tendency that alloys with lower "C" have higher " $m$ " was noticed (for example, see the Ti420A alloy behavior). This means that when $\Delta \mathrm{K}$ is closer to the threshold, the growth rate is lower. However, for higher $\Delta \mathrm{K}$, the rate is closer to that of other alloys. This can drive the design of mechanical components manufactured from these alloys.

Nonlinearity of crack growth rate in region II of the da/ $\mathrm{dN} x \Delta \mathrm{K}$ curve was found for the Ti420CR alloy. The transition was noticed by changing the slope of the curve in region II (Figure 4). The linear regressions of each zone allowed to give the new "C" and " $\mathrm{m}$ " for the alloy (Table 4). The crack growth rate behavior of the Ti420CR alloy underwent a smoother transition trend in $\Delta \mathrm{K}$ closer to $9 \mathrm{MPa} \sqrt{\mathrm{m}}$. Zone $\mathrm{A}$ of this curve has lower " $\mathrm{C}$ " and higher " $\mathrm{m}$ " if compared to zone B.

\subsection{Fracture analysis}

The metallographic analysis (Figure 5) aims to explain the reason for the different crack growth rate behaviors of all alloys. In studies conducted with the Ti6Al4V alloy, it has been reported that there is a change in the slope of region II of the $\mathrm{da} / \mathrm{dN} \mathrm{x} \Delta \mathrm{K}$ curve when the cyclic plastic zone at the crack tip becomes equal to the size of the Widmanstätten colonies $[14,15,30]$. However, in the present study, it was not possible to associate changes in the slope of the curve in this way, since the studied alloys have coarse microstructures in relation to the common sizes of the cyclic plastic zone at the crack tip. The plastic zone at the crack tip of our alloys is much smaller than the $\beta$ grains.

Table 3. Constants "C", " $\mathrm{m}$ " and $\mathrm{R}^{2}$ obtained from the Paris equation (region II of the da/dN x $\Delta \mathrm{K}$ curve) for each alloy tested at a loading rate of 0.1

\begin{tabular}{ccccc}
\hline Material & $\mathbf{C}[\mathbf{m} /(\mathbf{c y c l e} . \mathbf{M P a} \sqrt{\mathbf{m}})]$ & $\mathbf{m}(-)$ & $\mathbf{R}^{\mathbf{2}}$ & Reference \\
\hline Ti6A14V & $3,6 \times 10^{-11}$ & 2,73 & - & {$[29]$} \\
Ti62222S lamellar & $7,1 \times 10^{-13}$ & 4,00 & - & {$[27]$} \\
Ti62222S bimodal & $2,7 \times 10^{-13}$ & 4,70 & - & {$[27]$} \\
Ti352CR & $8 \times 10^{-12}$ & 4,29 & 0,97 & Present study \\
Ti352A & $9 \times 10^{-12}$ & 4,09 & 0,79 & Present study \\
Ti422CR & $4 \times 10^{-12}$ & 3,95 & 0,95 & Present study \\
Ti422A & $2 \times 10^{-11}$ & 3,54 & 0,97 & Present study \\
Ti420CR & $1 \times 10^{-11}$ & 4,00 & 0,94 & Present study \\
Ti420A & $4 \times 10^{-13}$ & 5,02 & 0,98 & Present study \\
\hline
\end{tabular}


Crack path analysis can explain transitions that occur in the Paris region in titanium alloys. Gao et al. [10] investigated the plastic zone at the crack tip of the Ti-6Al-2Zr-1Mo-1V alloy with tri-modal microstructure. Their results show that heterogeneous slip and secondary micro-cracks are the main features of the fatigue crack tip plastic zone. In particular, the lamellar $\alpha$ phase in the tri-modal microstructure can effectively deflect and delay the crack propagation, thus improving the alloy's fatigue life. The present study revealed that the transition that occurred in the Ti420CR alloy was encouraged by bifurcation and deflection of the crack (see

Table 4. "C", " $m$ " and $\mathrm{R}^{2}$ obtained from the Paris equation of the different zones formed in region II for Ti420CR alloys

\begin{tabular}{ccccc}
\hline Material & Zone & $\mathbf{C}[\mathbf{m} /($ cycle.MPa $\sqrt{\mathbf{m}})]$ & $\mathbf{m}(-)$ & $\mathbf{R}^{2}$ \\
\hline \multirow{2}{*}{ Ti420CR } & $\mathrm{A}$ & $4 \times 10^{-13}$ & 5,83 & 0,94 \\
& $\mathrm{~B}$ & $5 \times 10^{-10}$ & 2,60 & 0,87 \\
\hline
\end{tabular}

Figure 5). These crack features reduce the crack growth rate. Therefore, " $\mathrm{m}$ " in zone B decreased noticeably, due to the difficulty of the crack to propagate. Bifurcation and crack deflection of the Ti420CR alloy are regarded to accumulated plastic strain at the crack tip, which impairs the crack path and causes secondary cracks and tortuous paths. In Qiu et al. study [12], this same transition phenomenon in $\mathrm{da} / \mathrm{dN} \times \Delta \mathrm{K}$ curves were reported for Ti6Al2Sn4Zr (2 and 4) Mo alloys with coarse microstructures tested under $\mathrm{R}=0.1$, where the low crack growth rate in the initial stage of the Paris regime were associated with these exposed effects.

Crack tortuosity improves the fatigue crack growth rate performance of Ti422CR, Ti422A and Ti420A alloys, because tortuosity leads to roughness-induced crack closure effect, which is the most common closure effect found in titanium alloys, when in the presence of intrinsically coarse microstructures [15]. This effect improves the crack deflection, reducing the crack growth rate, which is also

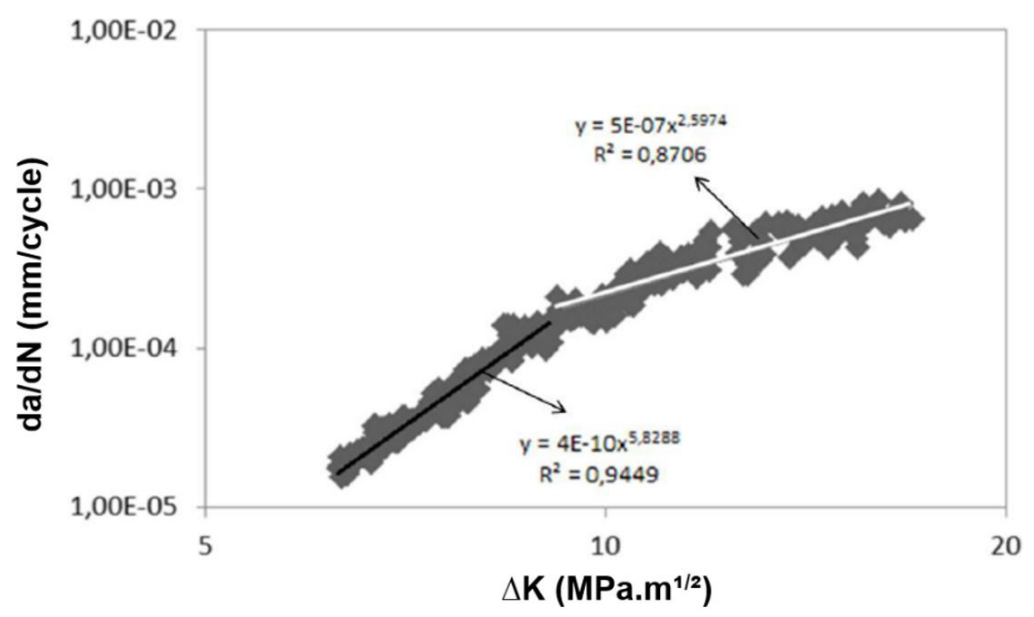

Figure 4. da/dN x $\Delta \mathrm{K}$ curve in the Paris regime for the Ti420CR alloy denotes two lines: black line (Zone A) and white line (Zone B).
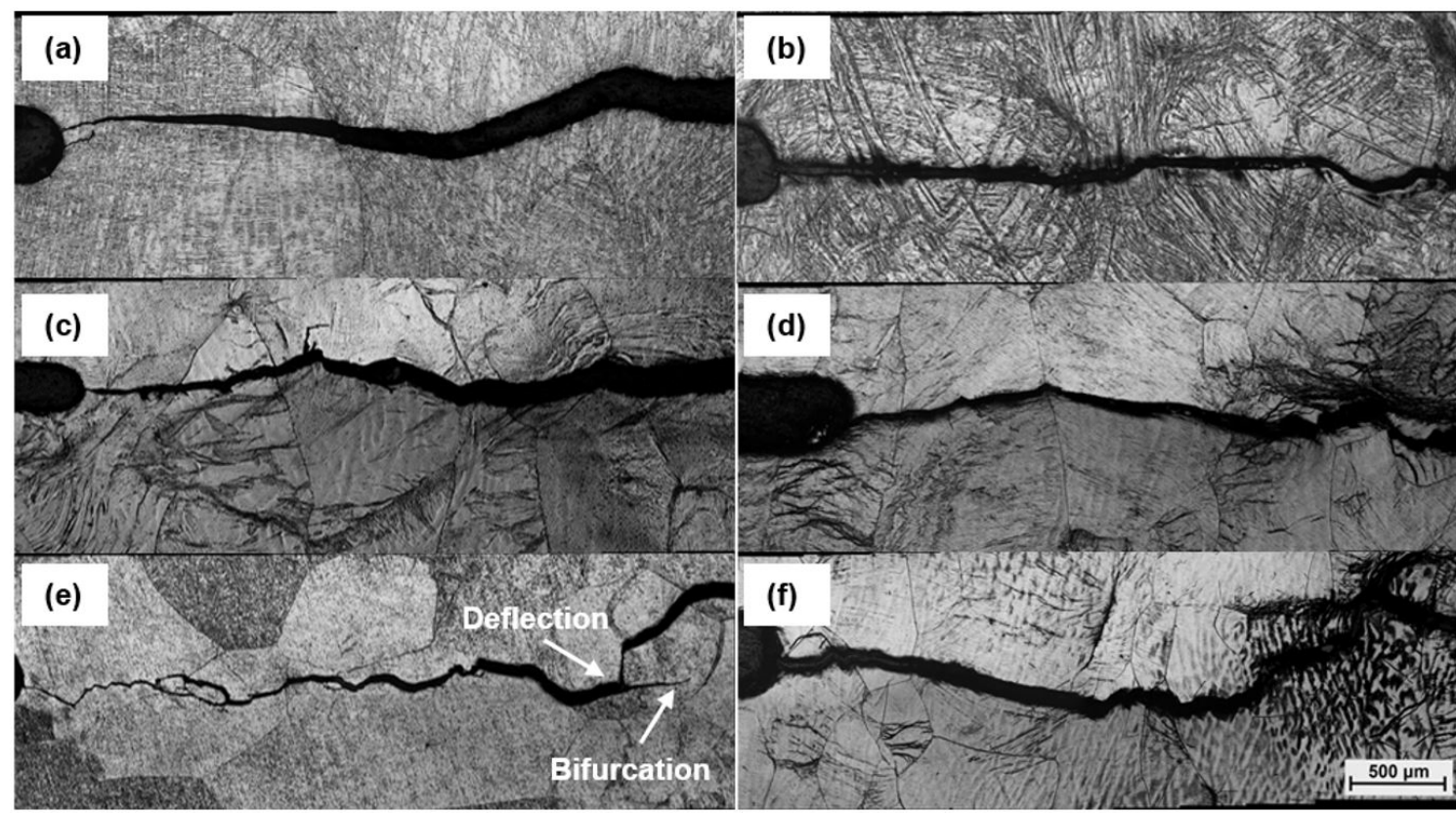

Figure 5. Profile of the crack propagation path for the (a) Ti352CR, (b) Ti352A, (c) Ti422CR, (d) Ti422A, (e) Ti420CR and (f) Ti420A alloys. 

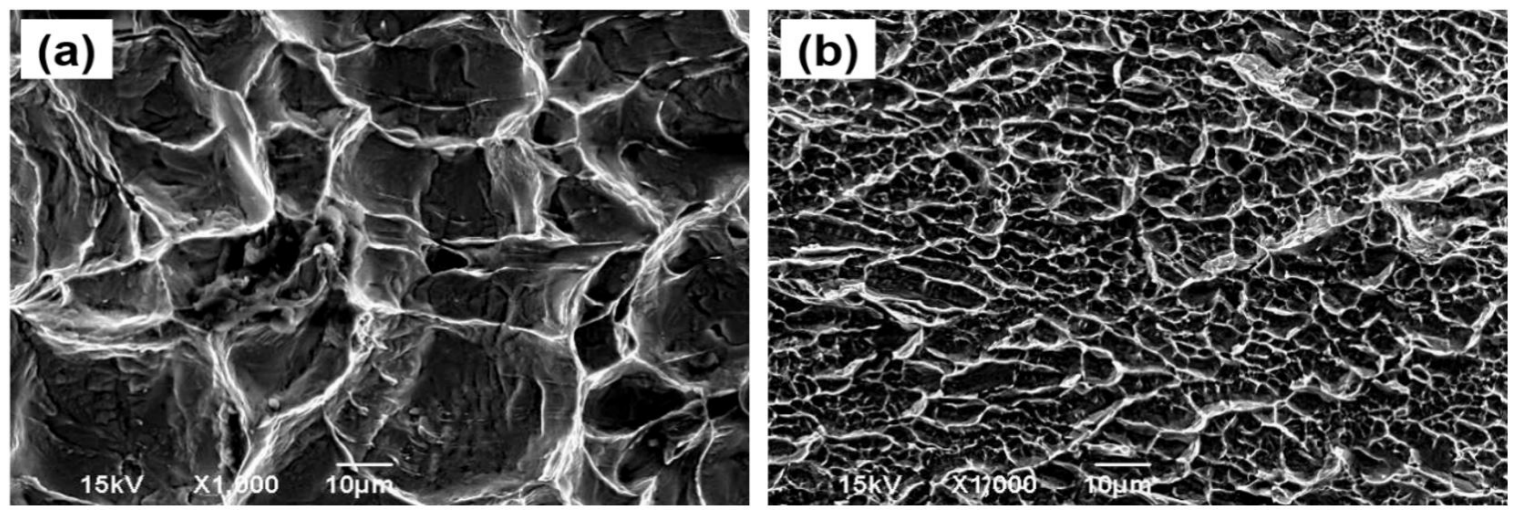

Figure 6. SEM analysis representative of the unstable fracture of the (a) cold rolled and (b) aged alloys.

reported in other alloys of coarse microstructures [31,32]. On the other hand, the Ti352A and Ti352CR alloys denoted straight crack paths and undergo poor performed regarding to crack growth rate. This behavior can be regarded to the higher amount of strain-induced martensite $(\alpha ")$ present in these alloys, due to the lower $\mathrm{Nb}$ content.

SEM analysis denote the fracture micromechanisms of the alloys. Figure 6 explain dimples in region III of the unstable fracture of the alloys, oriented according to the crack opening displacement direction. Larger and deeper dimples occur in cold worked alloys, while the aging promoted smaller and shallower dimples. Therefore, we can conclude that the finely dispersed $\alpha$ precipitates work as dimple nucleators.

\section{Conclusions}

This study was performed to evaluate the fatigue crack growth rate behavior of TiNbSn alloys, which was achieved by crack growth test and fracture analysis. According to the study, the following conclusions were given:
- The alloys chemical content does not influence qualitatively the $\Delta \mathrm{K}$ threshold of the alloys. However, aging tends to increase the $\Delta \mathrm{K}$ threshold;

- The addition of $\mathrm{Nb}$ and $\mathrm{Sn}$ enhances the crack growth rate performance of the alloys in region II, which were attributed to the crack tortuosity, that leads to the crack-closing effect induced by roughness. Aging also improves the crack growth rate performance of the alloys in region II, except for the Ti352 alloy;

- The transition in the region II of the crack growth rate curve was found for the Ti420CR alloy, which was regarded to crack bifurcation and deflection. These effects improve the crack growth rate behavior;

- Fine and dispersed $\alpha$ precipitates of aged alloys promote finer dimples as fracture micromechanics of the alloys.

\section{Acknowledgements}

The authors would like to thank the funding agencies CAPES, CNPq, FINEP and CBMM for providing Niobium.

\section{References}

1 Azevedo TF, de Andrade CEC, dos Santos SV, Silva AS, Griza S. Fatigue and corrosion-fatigue strength of hot rolled Ti35Nb2.5Sn alloy. Materials \& Design. 2015;85:607-612.

2 Griza S, de Souza Sá DHG, Batista WW, de Blas JCG, Pereira LC. Microstructure and mechanical properties of hot rolled TiNbSn alloys. Materials \& Design. 2014;56:200-208.

3 Jung TK, Lee HS, Semboshi S, Masahashi N, Abumiya T, Hanada S. A new concept of hip joint stem and its fabrication using metastable TiNbSn alloy. Journal of Alloys and Compounds. 2012;536(Suppl. 1):S582-S585.

4 Hanada S, Masahashi N, Jung TK, Yamada N, Yamako G, Itoi E. Fabrication of a high-performance hip prosthetic stem using $\beta$ Ti-33.6Nb-4Sn. Journal of the Mechanical Behavior of Biomedical Materials. 2014;30:140-149.

5 Azevedo TF, Lima TN, Macedo MD, de Blas JG, Griza S. Fracture mechanics behavior of TiNbSn alloys as a function of alloy content, cold working and aging. Engineering Fracture Mechanics. 2020;229:106946.

6 Azevedo TF, Lima TN, Blas JG, Pereira LC, Griza S. The mechanical behavior of TiNbSn alloys according to alloying contents, cold rolling and aging. Journal of the Mechanical Behavior of Biomedical Materials. 2017;75:33-40.

7 Shi XH, Zeng WD, Shi CL, Wang HJ, Jia ZQ. The effects of colony microstructure on the fatigue crack growth behavior for Ti-6A1-2Zr-2Sn-3Mo-1Cr-2Nb titanium alloy. Materials Science and Engineering A. 2015;621:252-258. 
8 Yoder GR, Cooley LA, Crooker TW. Observations on microstructurally sensitive fatigue crack growth in a widmanstaetten Ti-6Al-4V alloy. Metallurgical Transactions A. 1977;8A(11):1737-1743.

9 Peralta P, Villarreal T, Atodaria I, Chattopadhyay A. Mechanical length scales and their link to fatigue crack growth kinetics in beta-annealed Ti-6Al-4V. Scripta Materialia. 2012;66(1):13-16.

10 Gao PF, Lei ZN, Wang XX, Zhan M. Deformation in fatigue crack tip plastic zone and its role in crack propagation of titanium alloy with tri-modal microstructure. Materials Science and Engineering A. 2019;739:198-202.

11 Boyer RR. An overview on the use of titanium in the aerospace industry. Materials Science and Engineering A. 1996;213(1-2):103-114.

12 Qiu J, Feng X, Ma Y, Lei J, Liu Y, Huang A, et al. Fatigue crack growth behavior of beta-annealed Ti-6Al-2Sn4Zr-xMo ( $\mathrm{x}=2,4$ and 6) alloys: Influence of microstructure and stress ratio. International Journal of Fatigue. 2016;83:150-160.

13 Verdhan N, Bhende DD, Kapoor R, Chakravartty JK. Effect of microstructure on the fatigue crack growth behaviour of a near- $\alpha$ Ti alloy. International Journal of Fatigue. 2015;74:46-54.

14 Ravichandran KS, Dwarakadasa ES. Fatigue crack growth transitions in Ti-6Al-4V alloy. Scripta Metallurgica. 1989;23(10):1685-1690.

15 Ravichandran KS. Fatigue crack closure as influenced by microstructure in Ti-6Al-4V. Scripta Metallurgica et Materialia. 1990;24:1559-1563.

16 Adib AML, Baptista CARP. An exponential equation of fatigue crack growth in titanium. Materials Science and Engineering A. 2007;452-453:321-325.

17 Iost A, Lesage J. On the existence of a pivot point for stage II fatigue crack growth. Engineering Fracture Mechanics. 1990;36(4):585-596.

18 Chand S, Garg SBL. Crack propagation under constant amplitude loading. Eng. Fracfure Mech. 1985;21:1-30.

19 ASTM International. ASTM E399-19. Standard Test Method for Linear-Elastic Plane-Strain Fracture Toughness K Ic of Metallic Materials. Conshohocken: ASTM International.

20 ASTM International. ASTM E1290-08. Standard Test Method for Crack-Tip Opening Displacement (CTOD) Fracture Toughness Measurement. Conshohocken: ASTM International.

21 British Standards Institution - BSI. BS 7448-1. Fracture mechanics toughness tests. Method for determination of KIc, critical CTOD and critical J values of metallic materials. London: BSI.

22 International Organization - ISO. BS ISO 12108. Metallic materials — Fatigue testing — Fatigue crack growth method. Geneva: ISO.

23 Matsumoto H, Watanabe S, Hanada S. Microstructures and mechanical properties of metastable $\beta$ TiNbSn alloys cold rolled and heat treated. Journal of Alloys and Compounds. 2007;439(1-2):146-155.

24 Lopes ESN, Cremasco A, Afonso CRM, Caram R. Effects of double aging heat treatment on the microstructure, Vickers hardness and elastic modulus of Ti-Nb alloys. Materials Characterization. 2011;62(7):673-680.

25 Jung TK, Semboshi S, Masahashi N, Hanada S. Mechanical properties and microstructures of $\beta$ Ti-25Nb-11Sn ternary alloy for biomedical applications. Materials Science and Engineering C. 2013;33(3):1629-1635.

26 Boyce BL, Ritchie RO. Effect of load ratio and maximum stress intensity on the fatigue threshold in Ti-6Al-4V. Engineering Fracture Mechanics. 2001;68:129-147.

27 Kruger L, Grundmann N, Trubitz P. Influence of microstructure and stress ratio on fatigue crack growth in a Ti-622-22-S alloy. Materials Today: Proceedings. 2015;2S:S205-S211.

28 Zaiken E, Ritchie RO. Effects of microstructure on fatigue crack propagation and crack closure behavior in aluminum alloy 7150. Materials Science and Engineering. 1985;70:151-160.

29 Sun W, Ma Y, Huang W, Zhang W, Qian X. Effects of build direction on tensile and fatigue performance of selective laser melting Ti6Al4V titanium alloy. International Journal of Fatigue. 2020;130:105260.

30 Ravichandran KS. Fracture mode transitions during fatigue crack growth in Ti-6Al-4V alloy. Scripta Metallurgica et Materialia. 1990;24:1275-1280.

31 Zhu ML, Xuan FZ, Wang GZ. Effect of microstructure on fatigue crack propagation behavior in a steam turbine rotor steel. Materials Science and Engineering A. 2009;515(1-2):85-92.

32 Zaiken E, Ritchie RO. Effects of microstructure on fatigue crack propagation and crack closure behavior in aluminum alloy 7150. Materials Science and Engineering. 1985;70:151-160.

Received: 14 Aug. 2020

Accepted: 26 Apr. 2021 